\title{
Application of Lignin as Adsorbent for Silver (Ag) and Copper (Cu) on Electroplating Waste in Kota Gede
}

\author{
Nurcahyo Iman Prakoso \\ Department of Chemistry, Universitas Islam Indonesia, \\ nurcahyo.ip@uii.ac.id
}

\begin{abstract}
ABSTRAK
Lignin merupakan komponen dari kayu. Dalam dunia industri kertas, lignin merupakan komponen yang tidak digunakan dalam proses dan secara umum dihilangkan dengan pengolahan secara kimia. Di sisi lain, tandan kelapa sawit merupakan limbah sisa pemanfaatan buah kelapa sawit, dimana tandan ini juga mengandung lignin yang cukup tinggi.

Penelitian ini menggunakan lignin dari limbah sisa pemanfaatan buah kelapa sebagai biomassa untuk mengadsorpsi logam perak dan tembaga yang terkandung dalam limbah electroplating dengan melihat rasio massa lignin dan waktu kontak agar diperoleh hasil adsorbsi yang optimal. Variasi massa yang digunakan adalah $100 \mathrm{mg}, 200 \mathrm{mg}, 300 \mathrm{mg}, 400 \mathrm{mg}$, dan $500 \mathrm{mg}$. Sedangkan untuk variasi waktu kontak adalah 2 jam, 3 jam, 4 jam, 5 jam, 6 jam. Untuk variasi suhu adalah $30{ }^{\circ} \mathrm{C}, 40{ }^{\circ} \mathrm{C}, 50{ }^{\circ} \mathrm{C}, 60{ }^{\circ} \mathrm{C}$.

Hasil penelitian menunjukkan bahwa rasio massa lignin yang paling optimal dalam mengadsorpsi logam perak dan tembaga adalah $200 \mathrm{mg} / 50 \mathrm{~mL}$. Sedangkan waktu kontak yang paling optimal adalah 4 jam untuk parameter $\mathrm{Ag}$ dan 2 jam untuk parameter $\mathrm{Cu}$. Untuk suhu kontak yang paling optimal dalam mengadsorpsi logam $\mathrm{Ag}$ pada suhu $50^{\circ} \mathrm{C}$ dan untuk logam $\mathrm{Cu}$ yaitu pada suhu $30^{\circ} \mathrm{C}$.
\end{abstract}

Kata Kunci : Lignin, logam CU, logam Ag, adsorpsi

\begin{abstract}
Lignin was a component of wood and always eliminated by chemical processing in many industries. On the other hand, oil palm bunches were the waste of palm oil industry, where that also containing high lignin.

This study used lignin from residual waste of palm oil industry as biomass to adsorb silver (Ag) and copper $(\mathrm{Cu})$ metal that is contained in electroplating waste by looking at lignin mass ratio, temperature and time in order to obtain optimal adsorption condition. The mass variations used were $100 \mathrm{mg}, 200 \mathrm{mg}, 300 \mathrm{mg}, 400 \mathrm{mg}$, and $500 \mathrm{mg}$. While for the variation of contact time were 2 hours, 3 hours, 4 hours, 5 hours, 6 hours. For temperature variations were $30{ }^{\circ} \mathrm{C}, 40{ }^{\circ} \mathrm{C}$, $50{ }^{\circ} \mathrm{C}$, and $60{ }^{\circ} \mathrm{C}$.

The results showed that the most optimal lignin mass ratio in adsorbing silver and copper metals was $200 \mathrm{mg} / 50 \mathrm{~mL}$. While the most optimal contact time were 4 hours for $\mathrm{Ag}$ and 2 hours for $\mathrm{Cu}$. For the most optimum temperature in adsorbing $\mathrm{Ag}$ metal at $50{ }^{\circ} \mathrm{C}$ and for $\mathrm{Cu}$ metal at 30 ${ }^{\circ} \mathrm{C}$.
\end{abstract}

Key Words: lignin, $\mathrm{Ag}, \mathrm{Cu}$, adsorption 


\section{Pendahuluan}

Tandan kosong kelapa sawit (TKKS) merupakan hasil sisa dari industri Crude Palm Oil (CPO) yang keberlimpahannya sangat besar. Ketersediaan TKKS sangat menjanjikan dimana rata-rata dihasilkannya tandan kosong kelapa sawit dalam industri CPO mencapai $22 \%$ sampai $24 \%$ dari total berat tandan buah segar (Arif, 2012).

Menurut Suriyani (2009), senyawa yang terkandung dalam TKKS meliputi selulosa (41-46,5\%), hemiselulosa (25,3$33,8 \%)$, dan lignin $(27,6-32,5 \%)$. Salah satu senyawa yang dapat dimanfaatkan dari semua senyawa yang terkandung dalam TKKS adalah lignin. Hal ini dikarenakan lignin mempunyai gugus aktif yang dapat direaksikan dengan gugus lain. Secara umum lignin tersusun atas unit siringil, guaiasil, hidroksil $(-\mathrm{OH})$, parahidroksil propana, dan beberapa gugus aldehida (Sarkanen et al., 1980).

Melihat potensi dari lignin, maka beberapa peneliti mulai melakukan penelitian dalam bidang isolasi, sintesis senyawa turunannya dan lain-lain. Simatupang et al. (2012) melakukan isolasi lignin dari TKKS dimana rendemen lignin yang diperoleh sebesar 16,42\%.

Prakoso et al. (2016) melakukan isolasi lignin dengan menggunakan sistem autoklaf dimana $\mathrm{NaOH}$ yang digunakan seminimal mungkin dan tanpa didahului proses ekstraksi menggunakan kombinasi antara benzena dan etanol.

Keberadaan gugus-gugus fungsional yang mendukung kemampuan adsorpsi lignin terhadap logam-logam berat adalah gugus $\mathrm{OH}$ fenolik. Dalam hal ini, keberadaan gugus fenolik atau hidroksil (-OH) dalam lignin yang notabene bersifat basa Lewis, dapat dimanfaatkan dalam interaksi antara gugus $\mathrm{OH}$ dengan logam (asam lewis).

Perak $(\mathrm{Ag})$ dan tembaga $(\mathrm{Cu})$ adalah logam berat yang termasuk dalam kategori bahan beracun dan berbahaya dimana penggunaannya di industri terutama dalam industri electroplating, tekstil dan industri logam sangat diperlukan. Penelitian ini menitik beratkan pada limbah cair dari industri pengolahan perak di daerah Kotagede, Yogyakarta yang mengandung logam berat Tembaga $(\mathrm{Cu})$ dan Perak $(\mathrm{Ag})$. Limbah cair ini jika langsung dibuang ke saluran peresapan, atau ke lingkungan sekitar akan berpotensi mencemari badan perairan (Sekarwati et al., 2015).

Oleh karena itu, proses penanganan limbah yang mengandung unsur logam Ag dan $\mathrm{Cu}$ menjadi bagian yang sangat penting dalam industri. Metode adsorpsi logam berat $\mathrm{Ag}$ dan $\mathrm{Cu}$ menggunakan lignin sebagai 
adsorben dipandang sangat penting dengan memanfaatkan potensi interaksi antara gugus hidroksil dengan ion logam.

\section{Tujuan Penelitian}

Penelitian ini bertujuan untuk mengetahui rasio optimum antara lignin dengan limbah cair electroplating, waktu dan suhu kontak dalam proses penurunan kadar perak (Ag) dan tembaga $(\mathrm{Cu})$ dalam sampel limbah.

\section{Metode Penelitian}

\section{Alat}

Peralatan yang digunakan pada penelitian ini yaitu seperangkat alas gelas, seperangkat autoklaf kapasistas $2 \mathrm{~L}$, pH meter, shredder, penyaring Buchner, kertas saring Whatman42, oven, spektrometer infra merah (IR, Shimadzu Prestige-21), dan AAS (Perkin Elmer PinAAcle 900T) .

\section{Bahan}

Bahan-bahan yang digunakan pada penelitian ini adalah sampel limbah cair industri perak Kotagede, serabut TKKS, $\mathrm{NaOH}$ (pa), etanol teknis 96\%, akuades, dan $\mathrm{H}_{2} \mathrm{SO}_{4} 10 \%$.

\section{Cara Kerja}

\section{Preparasi sampel}

Sebanyak 100 gram serabut TKKS dikeringkan menggunakan oven pada suhu $100{ }^{\circ} \mathrm{C}$ kemudian dihancurkan menggunakan shredder menjadi ukuran 10 mesh. Sampel kemudian ditambahkan akuades 1 L dan dipanaskan pada suhu $100{ }^{\circ} \mathrm{C}$ selama 2 jam. Kemudian sampel difiltrasi dan dikeringkan sehingga siap digunakan.

\section{Isolasi Lignin}

Sebanyak 90 gram serbuk TKKS 10 mesh dimasukkan ke dalam autoklaf dan ditambahkan 1 L larutan 1\% (10 g) $\mathrm{NaOH}$ dalam akuadest : etanol 96\% (1:1). Sistem dipanaskan selama 5 jam dengan suhu 170 ${ }^{\circ} \mathrm{C}$ pada tekanan 15 atmosfir. Kemudian disaring dan diambil larutan lindi hitam yang terbentuk. Pada larutan lindi hitam dilakukan pengasaman menggunakan $\mathrm{H}_{2} \mathrm{SO}_{4} \quad 10 \%$ sampah $\mathrm{pH}$ 2. Campuran kemudian didiamkan selama 8 jam sampai terbentuk padatan. Padatan (lignin) yang terbentuk kemudian disaring menggunakan whatman 42 dan dipanaskan menggunakan oven pada suhu $60{ }^{\circ} \mathrm{C}$.

\section{Optimasi rasio lignin dengan limbah cair}

Lignin sebanyak $100 \mathrm{mg}, 200 \mathrm{mg}$, 300 mg, 400 mg dan 500 mg dimasukkan ke dalam $50 \mathrm{~mL}$ limbah cair. Campuran antara limbah dengan lignin diaduk selama 2 jam. 
Setelah itu, filtrat dianalisis kadar $\mathrm{Ag}$ dan $\mathrm{Cu}$ dengan metode AAS.

\section{Optimasi waktu kontak antara lignin} dengan limbah cair

Lignin sebanyak hasil paling optimal dalam percobaan I dikontakkan dengan limbah cair sebanyak $50 \mathrm{~mL}$. Campuran diaduk dengan waktu kontak optimum untuk masing-masing logam. Suhu kontak divariasikan $30^{\circ} \mathrm{C}, 40{ }^{\circ} \mathrm{C}, 50{ }^{\circ} \mathrm{C}$, dan $60^{\circ} \mathrm{C}$. Campuran disaring dan filtratnya diuji kadar $\mathrm{Ag}$ dan $\mathrm{Cu}$ menggunakan metode AAS.

\section{Optimasi suhu kontak antara lignin dengan limbah cair}

Lignin sebanyak hasil paling optimal dalam percobaan I dikontakkan dengan limbah cair sebanyak $50 \mathrm{~mL}$. Campuran diaduk dengan waktu kontak 2 jam, 3 jam, 4 jam, 5 jam, dan 6 jam. Setelah 2 jam, 3 jam, 4 jam, 5 jam, dan 6 jam, campuran disaring dan filtratnya diuji kadar $\mathrm{Ag}$ dan $\mathrm{Cu}$ menggunakan metode AAS.

\section{Hasil dan Pembahasan}

Penelitian ini bersifat eksploratif dimana nantinya akan didapatkan hasil akhir berupa kondisi optimum proses adsorpsi logam $\mathrm{Ag}$ dan $\mathrm{Cu}$ menggunakan lignin. Proses adsorpsi ini memanfaatkan adanya gugus hidroksil pada lignin sehingga diharapkan dapat berinteraksi dengan ion $\mathrm{Ag}^{+}$maupun $\mathrm{Cu}^{2+}$.

Kandungan $\mathrm{Ag}$ dan $\mathrm{Cu}$ yang masih terdapat dalam sampel limbah cair dikethaui terlebih dahulu. Hal ini dilakukan untuk mempermudah proses preparasi sampel limbah yang nantinya akan dianalisis menggunakan AAS. Seperti yang telah diketahui bahwa AAS limit deteksi dalam skala ppm sehingga kandungan awal Ag dan $\mathrm{Cu}$ sangatlah penting dalam pengambilan tindakan pengenceran maupun pemekatan sampel.

Dari analisis kandungan awal Ag dan $\mathrm{Cu}$ dalam sampel limbah cair diperoleh data bahwa Ag yang terkandung sebanyak 128 ppm dan $\mathrm{Cu}$ yang terkandung sebanyak 1.259 ppm. Konsentrasi awal $\mathrm{Ag}$ dan $\mathrm{Cu}$ tersebut berada di atas baku mutunya yaitu 0,5 mg/L sesuai Kep Men LH RI No. 5 Tahun 2014 Tentang Baku Mutu Air Limbah Bagi Usaha dan atau Kegiatan Industri Pelapisan Logam Dan Galvanis sehingga limbah cair ini tergolong tidak layak minum dan dibuang ke lingkungan karena konsentasi melebihi ambang batas maksimum.

Oleh karena untuk parameter $\mathrm{Cu}$ konsentrasinya 1.259 ppm maka dilakukan pengenceran sampai konsentrasinya menjadi 
107,2 ppm sementara untuk parameter $\mathrm{Ag}$ tidak dilakukan pengenceran. Sampel limbah cair kemudian dibuat dalam volume sama yaitu $50 \mathrm{~mL}$.

Pada proses optimasi rasio lignin/limbah cair didapatkan fakta bahwa $\mathrm{Ag}$ dan $\mathrm{Cu}$ teradsorpsi paling banyak pada rasio lignin/limbah $200 \mathrm{mg} / 50 \mathrm{~mL}$ dimana Ag yang teradsorpsi sebanyak 125,56 ppm dan $\mathrm{Cu}$ yang teradsorpsi sebanyak 7,97 ppm. Hal ini diperjelas pada Tabel 1 dan Grafik 1 dan 2.

Tabel 1. Efek rasio lignin/ $50 \mathrm{~mL}$ limbah cair terhadap Ag dan $\mathrm{Cu}$ yang teradsorpsi

\begin{tabular}{|c|c|c|c|}
\hline No & $\begin{array}{c}\text { Lignin } \\
(\mathrm{mg})\end{array}$ & $\begin{array}{c}\text { Kadar Ag } \\
\text { yang } \\
\text { teradsorpsi } \\
(\mathrm{ppm})\end{array}$ & $\begin{array}{c}\text { Kadar } \mathrm{Cu} \\
\text { yang } \\
\text { teradsorpsi } \\
(\mathrm{ppm})\end{array}$ \\
\hline 1 & 100 & 124,91 & 7,22 \\
\hline 2 & 200 & 125,56 & 7,97 \\
\hline 3 & 300 & 124,54 & 7,86 \\
\hline 4 & 400 & 124,88 & 7,72 \\
\hline 5 & 500 & 124,72 & 7,35 \\
\hline
\end{tabular}

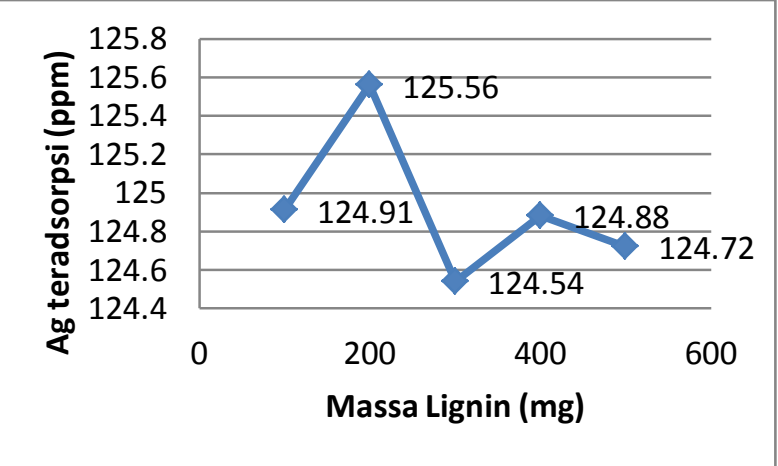

Gambar 1. Kadar Ag yang teradsorpsi

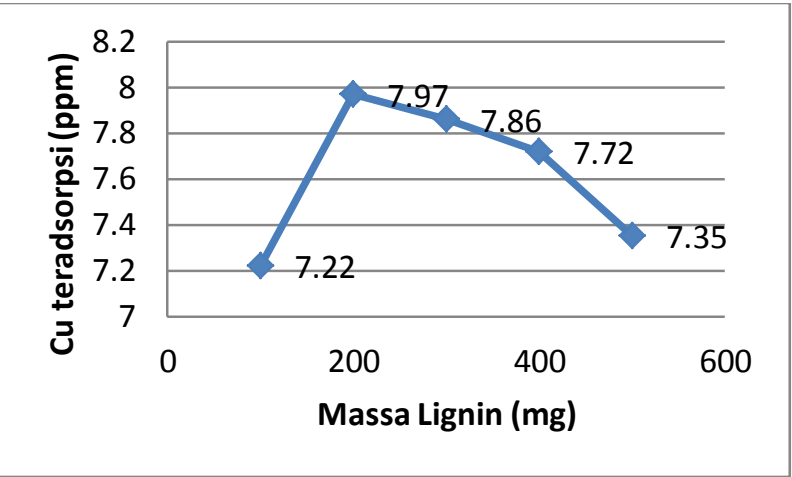

Gambar 2. Kadar $\mathrm{Cu}$ yang teradsorpsi

Dari hasil ini, maka dapat ditentukan rasio optimum lignin/ $50 \mathrm{~mL}$ limbah cair adalah 200 mg. Rasio ini kemudian digunakan sebagai acuan dalam proses optimasi waktu kontak lignin dengan limbah cair.

Tabel 2. Efek waktu kontak lignin dengan limbah cair terhadap adsorpsi Ag dan $\mathrm{Cu}$

\begin{tabular}{|c|c|c|c|}
\hline No & $\begin{array}{c}\text { Waktu } \\
\text { Kontak } \\
\text { (jam) }\end{array}$ & $\begin{array}{c}\text { Kadar Ag } \\
\text { yang } \\
\text { teradsorpsi } \\
\text { (ppm) }\end{array}$ & $\begin{array}{c}\text { Kadar Cu } \\
\text { yang } \\
\text { teradsorpsi } \\
\text { (ppm) }\end{array}$ \\
\hline 1 & 2 & 125,57 & 7,97 \\
\hline 2 & 3 & 125,71 & 0,39 \\
\hline 3 & 4 & 125,85 & 7,22 \\
\hline 4 & 5 & 125,85 & 6,74 \\
\hline 5 & 6 & 125,85 & 6,26 \\
\hline
\end{tabular}

Untuk mengetahui waktu kontak yang paling optimal dari proses adsorpsi Ag dan $\mathrm{Cu}$ menggunkan lignin, dilakukan variasi lama waktu kontak yaitu 2, 3, 4, 5, dan 6 jam. Waktu kontak yang optimum dalam 
proses adsorpsi Ag adalah 4 jam dan 2 jam untuk adsorpsi $\mathrm{Cu}$. Hasil disajikan pada Tabel 2, Gambar 3 dan 4

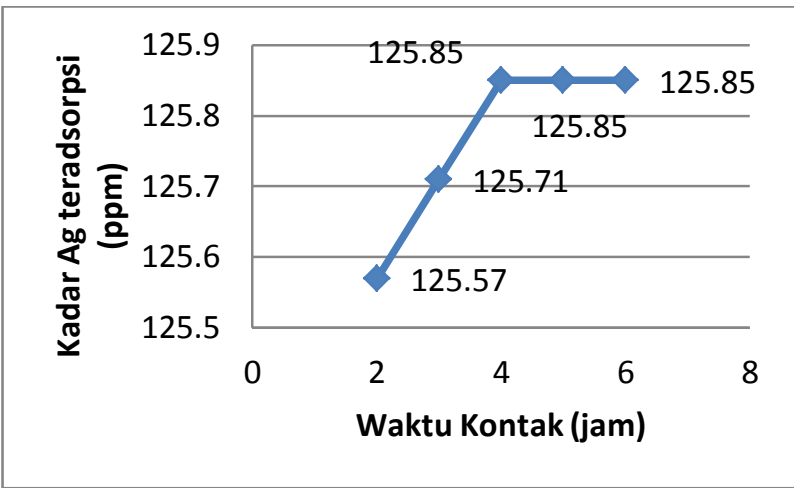

Gambar 3. Kadar Ag yang teradsorpsi

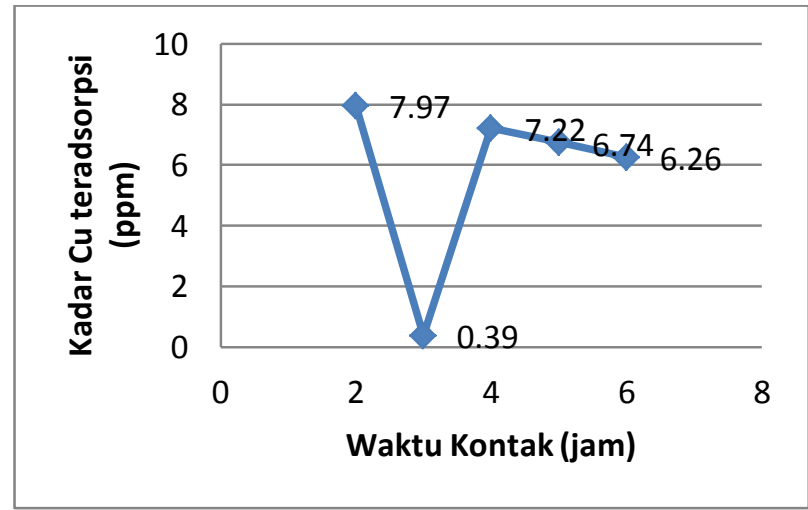

Gambar 4. Kadar $\mathrm{Cu}$ yang teradsorpsi

Hal terakhir adalah optimasi suhu kontak adsorpsi dimana dalam perlakuannya digunakan rasio lignin/limbah cair dan waktu kontak optimum untuk masing-masing logam. Adsorpsi Ag menggunakan lignin sebanyak 200 mg dengan waktu kontak 4 jam dan $\mathrm{Cu}$ menggunakan lignin sebanyak 200 mg dengan waktu kontak 2 jam. Variasi suhu kontak yang dilakukan adalah 30, 40,
50 dan $60{ }^{\circ} \mathrm{C}$. Hasil variasi ini ditunjukkan pada Tabel 3, Gambar 5 dan 6.

Tabel 3. Efek suhu kontak lignin dengan limbah cair terhadap adsorpsi $\mathrm{Ag}$ dan $\mathrm{Cu}$

\begin{tabular}{|c|c|c|c|}
\hline No & $\begin{array}{c}\text { Suhu } \\
\text { kontak } \\
\left({ }^{\circ} \mathrm{C}\right)\end{array}$ & $\begin{array}{c}\text { Kadar Ag } \\
\text { yang } \\
\text { teradsorpsi } \\
(\mathrm{ppm})\end{array}$ & $\begin{array}{c}\text { Kadar Cu } \\
\text { yang } \\
\text { teradsorpsi } \\
(\mathrm{ppm})\end{array}$ \\
\hline 1 & 30 & 125,85 & 7,97 \\
\hline 2 & 40 & 128,14 & 7,90 \\
\hline 3 & 50 & 128,20 & 7,61 \\
\hline 4 & 60 & 128,19 & 2,26 \\
\hline
\end{tabular}

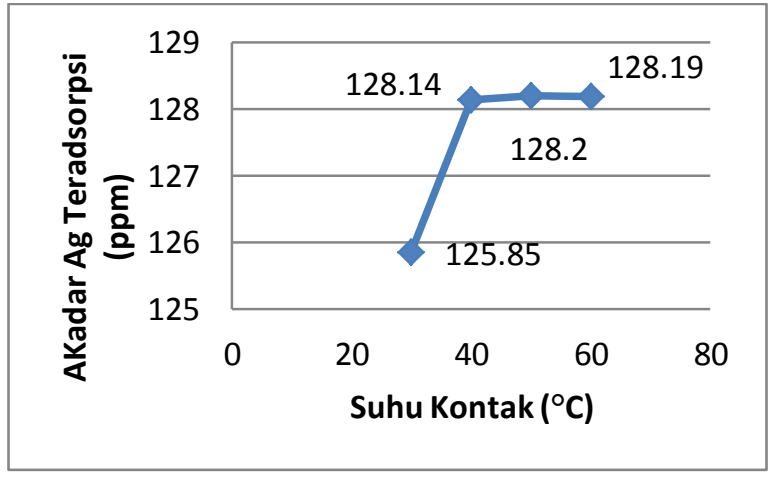

Gambar 5. Kadar Ag yang teradsorpsi

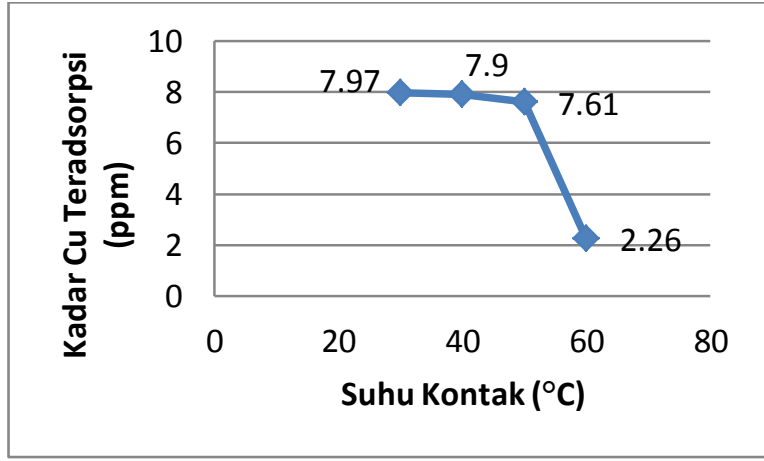

Gambar 6. Kadar $\mathrm{Cu}$ yang teradsorpsi 
Suhu kontak optimum yang didapatkan dari proses adsorpsi dengan lignin yaitu 50 ${ }^{\circ} \mathrm{C}$ untuk adsorpsi $\mathrm{Ag}$ dan $30{ }^{\circ} \mathrm{C}$ untuk adsorpsi $\mathrm{Cu}$. Semakin tinggi suhu kontak yang digunakan, daya adsoprsi lignin terhadap $\mathrm{Ag}$ ataupun $\mathrm{Cu}$ cenderung menurun. Hal ini dimungkinkan karena terjadinya degradasi lignin yang dibersamai dengan proses pengendapan logam tersebut saat suhu kontak meningkat sehingga tidak dapat teradsorpsi oleh lignin.

\section{Kesimpulan}

Telah didapatkan kondisi optimum untuk proses adsorpsi $\mathrm{Ag}$ yaitu menggunakan rasio lignin $200 \mathrm{mg} / 50 \mathrm{~mL}$ limbah pada suhu $50{ }^{\circ} \mathrm{C}$ dengan waktu 4 jam. Kondisi optimum untuk proses adsorpsi $\mathrm{Cu}$ yaitu menggunakan rasio lignin $200 \mathrm{mg} /$ $50 \mathrm{~mL}$ limbah pada suhu $30{ }^{\circ} \mathrm{C}$ dengan waktu 2 jam.

\section{Pustaka}

Arif, Z., 2012, Respon Parking Bumper Bahan Komposit Polymeric Foam Diperkuat Serat Tandan Kosong Kelapa Sawit (Tkks) Akibat Beban Tekan Statik Dan Dinamik (Simulasi Numerik), Tesis Master, Universitas Sumatera Utara.
Prakoso, N.I., Purwono, S., dan Rocmadi, 2016, Study on Lignin Isolation from Oil Palm Empty Fruit Bunches, Eksakta: Jurnal Ilmu-Ilmu MIPA, ISSN: 2503-2364, pp.46-54.

Sarkanen, K., V. S. Assiz and V. Chiang. 1980, Organosolv Pulping. Semi annual Report I and II. College of Forest Resources, Univ. of Washington, New York.

Sekarwati, N., Murachman, B., dan Sunarto, 2015, Dampak Logam Berat $\mathrm{Cu}$ (Tembaga) Dan Ag (Perak)Pada Limbah Cair Industri Perak Terhadap Kualitas Air Sumur Dan Kesehatan Masyarakat Serta Upaya Pengendaliannya Di Kota Gede Yogyakarta, Jurnal EKOSAINS, VII, pp. 64-76.

Simatupang, H., Nata, A., dan Herlina, N., 2012, Studi Isolasi dan Rendemen Lignin Dari Tandan Kosong Kelapa Sawit (TKKS), Jurnal Teknik Kimia $U S U, 1,20-24$.

Suriyani, Y., 2009, Utilization of Biomass Waste Empty Fruit Bunch Fiber of Palm Oil for Bioethanol Production, Jakarta 4-5 Februari 2009 : Research Workshop on Sustainable Biofuel : 115. 